\title{
O DANO MORAL NAS RELAÇÕES DE CONSUMO EM FACE DA ANÁLISE ECONÔMICA DO DIREITO
}

\section{THE MORAL DAMAGE IN CONSUMER RELATIONS AT THE PERSPECTIVE ECONOMIC ANALYSIS OF LAW.}

\author{
${ }^{1}$ Antonio Francisco Frota Neves
}

\section{RESUMO}

Este artigo analisa a responsabilidade civil, segundo o ordenamento jurídico brasileiro, sob o ângulo do dano moral, nas relações de consumo. Parte-se de uma compreensão dos instrumentos legais, tanto na lei geral (CCB) quanto na lei especial (CDC) de forma a apurar o instrumental utilizado pelo Poder Judiciário e em especial pelo STJ. Utiliza-se a análise econômica do direito em face da responsabilidade civil, servindo-se de método e ferramenta auxiliar para encontrar soluções que possam produzir desestímulos àqueles que relutam nas precauções com o fito de inibir ou reduzir os danos causados aos consumidores.

Palavras-chave: Análise econômica do direito, Responsabilidade civil, Acidentes nas relações de consumo, Dano moral, Dano material

\begin{abstract}
This article analyzes the liability, according to the Brazilian legal system, from the standpoint of moral damage, in consumer relations. It starts with an understanding of the legal instruments, both in the general law (CCB) and the special law (CDC) to determine the instrument used by the judiciary and especially the Supreme Court. It uses the economic analysis of law in the face of civil responsibility, serving up method and auxiliary tool to find solutions that can produce disincentives to those who are reluctant in precautions with the aim to inhibit or reduce the damage caused to consumers.
\end{abstract}

Keywords: Law and economics, Liability, Accidents in consumer relations, Moral damage, Material damage

\footnotetext{
${ }^{1}$ Mestre em Direito pela Universidade Católica de Brasília - UCB, Distrito Federal (Brasil). Professor pela Faculdade Projeção - FAPRO, Distrito Federal (Brasil). E-mail: advfrota@yahoo.com.br
} 


\section{Introdução}

Várias são as ciências que se preocupam com o comportamento humano. A Sociologia, a Psicologia, a Psiquiatria, a Criminologia, a Economia, o Direito, dentre outras. Entretanto, como ciência normativa, o Direito é a que mais se preocupa e gera efetividade na pacificação social. E a paz social é conseguida, precipuamente, pelo desestímulo que são oferecidos aos indivíduos para o não exercício da autotutela em contrapartida àqueles que, eventualmente, causem-lhe algum dano.

E é nesse sentir que a presente pesquisa tem como escopo o dano moral, nas relações de consumo, que se enxergando o arcabouço jurídico atual, tem sido insuficiente para produzir desestímulos àqueles que teimam colocar produtos e serviços no mercado de consumo, eivados de vícios e defeitos, que sob a ótica da análise econômica do direito, as condenações impostas aos causadores de tais danos, a relação custo/benefício continuam favoráveis aos fornecedores/produtores de bens e serviços.

Retiradas as excepcionalíssimas oportunidades em que o Estado autoriza a autotutela, é seu o monopólio de resolver os conflitos entre os indivíduos e faz isso por meio das normas estampadas no ordenamento jurídico, cuja concretude se perfaz com a Jurisdição - dizer o direito, ou quando se tratar de casos em que se admite, pela arbitragem.

Uma das finalidades da jurisdição é impor responsabilidade ${ }^{1}$ àquele que cometeu um ato ilícito. Este ilícito poderá ter natureza penal, administrativa ou civil. O presente artigo limitase em analisar, apenas os ilícitos previstos no Código de Defesa do Consumidor - CDC, em seu artigo 12 (Da responsabilidade pelo fato do produto e do serviço), em consonância com o estabelecido na ordem civil, conforme definido no Código Civil Brasileiro - CCB/2002: "(i) art. 186: Aquele que, por ação ou omissão voluntária, negligência ou imprudência, violar direito e causar dano a outrem, ainda que exclusivamente moral, comete ato ilícito"; sendo que logo em seguida, define claramente o abuso do direito, nos termos, “(ii) art. 187 - Também comete

\footnotetext{
${ }^{1}$ Código Civil Brasileiro - artigo 927: Aquele que, por ato ilícito (arts. 186 e 187), causar dano a outrem, fica obrigado a repará-lo.

Parágrafo único. Haverá obrigação de reparar o dano, independentemente de culpa, nos casos especificados em lei, ou quando a atividade normalmente desenvolvida pelo autor do dano implicar, por sua natureza, risco para os direitos de outrem.
} 
ato ilícito o titular de um direito que, ao exercê-lo, excede manifestamente os limites impostos pelo seu fim econômico ou social, pela boa-fé ou pelos bons costumes”.

Nessa toada, a mesma lei civil traz algumas excludentes dessa ilicitude, apontando no art. 188 - "Não constituem atos ilícitos: (a) os praticados em legítima defesa ou no exercício regular de um direito reconhecido"; ou seja, excepcionando tal comportamento como não contrário ao direito, e ainda, “(b) a deterioração ou destruição da coisa alheia, ou a lesão à pessoa, a fim de remover perigo iminente, nesse caso, o ato será legítimo somente quando as circunstâncias o tornarem absolutamente necessário", entretanto, tal conduta não poderá exceder os limites do indispensável para a remoção do perigo.

E desse modo, aquele que cometer um ato ilícito, não acobertado por nenhuma das excludentes de responsabilidade, taxativamente previstas pelo legislador, tem a obrigação de reparar o dano, ainda que exclusivamente moral. E é apenas esta última espécie de dano que será tratado nesta pesquisa - o dano moral - aquele ligado diretamente aos direitos da personalidade, portanto excluído toda e qualquer forma de indenização material. E que para França (1975, p. 403), “direitos da personalidade dizem-se as faculdades jurídicas cujo objeto são os diversos aspectos da própria pessoa do sujeito, bem assim as suas emanações e prolongamentos".

É nesse escopo que o presente artigo trilhará na busca da identificação da melhor resposta do Estado à reparação do dano moral decorrente dos acidentes nas relações de consumo. Como melhor resposta entender-se-ia aquela que gerasse suficiente desestímulo à sociedade como um todo a repetir condutas ensejadoras de causarem danos a outrem. Melhor resposta aliada ao conceito de eficiência econômica, de sorte que o aparato do Estado movimentado para pacificar os conflitos sociais, pudesse entregar a jurisdição com maior e melhor qualidade, utilizando-se da menor quantidade possível de recursos públicos.

Quanto à análise econômica do direito, este artigo não objetiva demonstrar os mais variados argumentos da ciência econômica para justificar a necessidade da sua utilização pelos que decidem o quantum de indenização imporá aos que violarem os direitos de outrem e lhes causarem prejuízos. Contudo, procura-se demonstrar também que as ferramentas econômicas são utilizadas pelos fornecedores de bens ou serviços no momento em que decidem se elevam ou não, seus custos de transação com maiores ou menores medidas de precaução a evitar danos a terceiros. 
O comportamento humano, exceto de alguns poucos acometidos por transtornos psíquico-sociais, tem razoável medida de racionalidade. É portanto, da própria natureza humana a racionalidade. Se assim é, o agir humano, ou seja, as escolhas que os povos civilizados encontraram para harmonizar os conflitos sociais e efetuadas diuturnamente são racionais. E o direito foi e é desde a formação dos primeiros grupos sociais, ainda que de forma incipiente, o instrumento abalizador para a solução dos conflitos inerentes à vida em sociedade.

É função do direito criar uma estrutura de incentivos a estimular ou desestimular comportamentos humanos cujo desiderato seja a pacificação social. Percebe-se muito claramente que os atuais incentivos ou desestímulos não têm sido suficientes para apresentar de forma eficiente tal objetivo.

\section{A Responsabilidade Civil nas Relações de Consumo}

Com a edição do Código de Defesa do Consumidor - CDC, Lei 8.078/1990, materializou-se de forma muito clarificada, a consagração da reparabilidade de danos morais oriundos da relação de consumo, garantidos como direito básico do consumidor (artigo $6^{\circ}$., inciso VI). É bem verdade que o CDC apenas cumpriu os desígnios determinados pela Constituição Federal de 1988 - CF/1988, ao exarar em seu artigo 5., inciso X: "são invioláveis a intimidade, a vida privada, a honra e a imagem das pessoas, assegurado o direito à indenização pelo dano material ou moral decorrente de sua violação".

O dano moral, no bojo do ordenamento jurídico pátrio, vem devidamente regrado a partir da CF/1988, passando pela legislação civilista até alcançar sua especialíssima proteção, no âmbito das relações consumeristas, conforme já declinado pelo CDC, em seu artigo $6^{\circ}$., inciso VI. Com isso, traz-se uma orientação indutora de comportamentos a serem observados pela sociedade brasileira, sinalizando a ojeriza que ao Direito causa a violação aos elementos essenciais da personalidade humana (BITTAR, 1994, p. 41).

Dessa forma, tratou-se da responsabilidade civil subjetiva, como aquela em que há a necessidade do elemento culpa do agente causador do dano, cuja relação jurídica esteja consubstanciada em um nexo de causalidade, resultando, inexoravelmente, em um prejuízo em face do ilícito cometido. Entretanto, o CDC faz distinção entre dois modelos de responsabilidade: (i) por vícios de qualidade ou quantidade de produtos ou serviços, e (ii) por danos causados aos consumidores, comumente conhecidos por acidentes de consumo. 
O CDC em seu artigo 12 traz o regramento acerca dos chamados acidentes de consumo em que trata da responsabilidade do fornecedor por danos decorrentes dos vícios de qualidade dos bens, bem como dos defeitos também decorrentes de projeto, fabricação, construção, montagem, fórmulas, manipulação, apresentação ou acondicionamento dos produtos (GRINOVER, 1997, p. 141).

Conforme a doutrina de Stoco (2004, p. 129) não há responsabilidade sem a ocorrência de prejuízo e este se traduz pelo dano, que se reverte no elemento essencial indispensável à responsabilização do agente, seja esta obrigação originada de um ato lícito, nas hipóteses expressamente previstas; de algum ato ilícito ou do inadimplemento contratual, independente, ainda, de se tratar de responsabilidade objetiva ou subjetiva.

$\mathrm{O}$ CCB/2002 adotou, paralelamente à cláusula geral de responsabilidade subjetiva do artigo 186, a cláusula geral de responsabilidade objetiva para as atividades de risco, conforme preceituado no artigo 927, em seu parágrafo único. Segundo Tepedino (2006, p. 807), a redação da cláusula geral prevista nesse dispositivo da lei civil, por sua amplitude, não se mostra precisa, considerando que toda e qualquer atividade implica, em alguma medida, por sua própria natureza, riscos para os direitos de outrem. Entretanto, salienta esse autor, quis se referir somente àquelas atividades que ofereçam alto risco ou um risco maior que o normal, isso justificaria um sistema mais severo de responsabilização.

Ao analisar-se o CDC, percebe-se que o legislador previu como excludente de responsabilidade, concernente à culpa da vítima, somente nos casos de culpa exclusiva do consumidor ou de terceiros. Em outras palavras, significa dizer que nos casos de culpa concorrente, o legislador não autorizou, pelo menos expressamente, a redução do valor de eventual indenização em que a vítima em alguma medida tivesse contribuído para o desiderato danoso (GARCIA, 2006, p. 47).

Apesar da ausência de previsibilidade legal, o STJ vem procedendo à redução do valor da indenização quando as instâncias a quo não têm levado em consideração a culpa concorrente da vítima para o desfecho do evento danoso, conforme se pode ver adiante:

STJ, REsp. 287849/SP, DJU: 13/08/2001, Rel. Min. Ruy Rosado de Aguiar, J. 17/04/2001. $4^{\text {a }}$. Turma.

CÓDIGO DE DEFESA DO CONSUMIDOR. Responsabilidade do fornecedor. Culpa concorrente da vítima. Hotel. Piscina. Agência de viagens. 


\begin{abstract}
- Responsabilidade do hotel, que não sinaliza convenientemente a profundidade da piscina, de acesso livre aos hóspedes. Art. 14 do CDC,

- A culpa concorrente da vítima permite a redução da condenação imposta ao fornecedor. Art. $12, \S 3^{\circ}$, III, do CDC.

- A agência de viagens responde pelo dano pessoal que decorreu do mau serviço do hotel contratado por ela para a hospedagem durante o pacote de turismo.

- Recursos conhecidos e providos em parte.
\end{abstract}

Assim, Alvim (1995, p. 22) referindo-se ao Código de Defesa do Consumidor entende que "o sistema do Código não exclui a culpa concorrente como atenuante de responsabilidade. Até porque a razão de ser que leva a culpa concorrente seja considerada como atenuante de responsabilidade é precisa e exatamente a mesma daquela segundo a qual é causa excludente a culpa exclusiva do consumidor".

\title{
3. Enquadramento Jurídico da Responsabilidade Civil Objetiva: Nexo Causal e Dano
}

A responsabilidade civil objetiva pode decorrer tanto das relações contratuais quanto das extracontratuais. E pelo fato de que tal responsabilidade independe do elemento culpa (imprescindível na responsabilidade civil subjetiva), poderá advir de um ato ilícito como também de uma conduta perfeitamente autorizada em lei, ou seja, sem nenhuma contrariedade ao direito, portanto um ato lícito, conforme se depreende do CCB/2002 (artigo 927, parágrafo único) e CDC (artigo 14) 2 .

Assim, na modalidade objetiva, o primeiro elemento da responsabilidade é o nexo causal. E conforme preleciona Cavalieri Filho (2004, p. 66), o conceito de nexo causal não diz respeito ao direito, trata-se de um fenômeno metajurídico, pois decorre das leis naturais e diz ele: “é um vínculo, a ligação ou relação de causa e efeito entre a conduta e o resultado". E mais adiante acrescenta “[...] estabelece o vínculo entre um determinado comportamento e um

\footnotetext{
2 CDC, Art. 14. O fornecedor de serviços responde, independentemente da existência de culpa, pela reparação dos danos causados aos consumidores por defeitos relativos à prestação dos serviços, bem como por informações insuficientes ou inadequadas sobre sua fruição e riscos.

$\S 1^{\circ} \mathrm{O}$ serviço é defeituoso quando não fornece a segurança que o consumidor dele pode esperar, levando-se em consideração as circunstâncias relevantes, entre as quais:

I - o modo de seu fornecimento;

II - o resultado e os riscos que razoavelmente dele se esperam;

III - a época em que foi fornecido.

$\S 2^{\circ}$ O serviço não é considerado defeituoso pela adoção de novas técnicas.

$\S 3^{\circ} \mathrm{O}$ fornecedor de serviços só não será responsabilizado quando provar:

I - que, tendo prestado o serviço, o defeito inexiste;

II - a culpa exclusiva do consumidor ou de terceiro.

$\S 4^{\circ} \mathrm{A}$ responsabilidade pessoal dos profissionais liberais será apurada mediante a verificação de culpa.
} 
evento, permitindo concluir, com base nas leis naturais, se a ação ou omissão do agente foi ou não a causa do dano."

Na mesma direção Pereira (1998, p. 76) observa que a relação de causalidade consiste na "determinação de elementos objetivos, externos, consistentes na atividade ou inatividade do sujeito, atentatórias do direito alheio", o que é corroborado por Gonçalves $(2006,384)$ em que enfatiza que "é necessário que se torne absolutamente certo que, sem esse fato, o prejuízo não poderia ter lugar”. O que se nota é que todos chegam à mesma conclusão de Cavalieri Filho, é indubitável que o nexo causal ou a relação de causalidade entre um evento danoso e o respectivo prejuízo (resultado) depende e está alinhado a um fenômeno natural não dominado pela ciência jurídica.

A exclusão da relação de causalidade, nas relações de consumo, poderá ocorrer em decorrência de, basicamente, três fenômenos, listados no CDC, art. 12, § $3^{\circ}{ }^{3}$. Entretanto, tanto a doutrina como a jurisprudência tem debatido a questão da possibilidade ou não de exclusão do nexo causal em função do caso fortuito e força maior.

Nery Júnior (1992, p. 56) assevera que a lista de excludentes contida no CDC está em numerus clausus, ou seja, trata-se de rol taxativo, não permitindo inclusão de outras excludentes em decorrência de analogia ou interpretação analógica.

Porém, o próprio STJ já se manifestou para acolher o caso fortuito e a força maior como excludente de responsabilidade (STJ, REsp. 350523/SP, DJU 25.03.2002, p. 278, Rel. Min. Carlos Alberto Menezes Direito, J. 11.12.2001, 3ª Turma). E tal posicionamento vem manifestado na doutrina de Cavalieri Filho (2004, p. 85) em que leciona: "O caso fortuito e a força maior excluem o nexo causal por constituírem também causa estranha à conduta do aparente agente, ensejadora direta do evento."

O segundo elemento é o próprio dano, que em última análise é o grande protagonista da responsabilidade civil. Sem o dano, não há que se falar em responsabilidade. E classifica-se em dano patrimonial e extrapatrimonial. Por não se tratar do objeto do presente artigo, apenas registre-se que o dano patrimonial atinge os bens integrantes do patrimônio da vítima, entendido

\footnotetext{
${ }^{3} \mathrm{CDC}$, art. $12, \S 3^{\circ}$.: “o fabricante, o construtor, o produtor ou importador só não será responsabilizado quando provar: I - que não colocou o produto no mercado; II - que, embora haja colocado o produto no mercado, o defeito inexiste; III - a culpa exclusiva do consumidor ou de terceiro."
} 
esse como todo um conjunto de relações jurídicas apreciáveis economicamente, também conhecido como dano material.

Em relação ao dano moral, ficou superada a questão se é indenizável ou não; ou se pode ser cumulado com os danos materiais. Essa discussão já pertence ao passado. O que se discute ainda é sua substância, ou seja, definir sua própria ocorrência.

O dano moral vem conceituado na doutrina nas formas mais diversas possíveis, dentre elas, a que faz por negativa dos danos patrimoniais, ou seja, afirmando que dano moral seria todo aquele cujo prejuízo não fosse patrimonial. Tal conceito é logicamente inservível, pois em nada esclarece a substância do dano moral (CAHALI, 1999, p. 42).

Para Cavalieri Filho (2004, p. 4) a conceituação do dano moral deve ser atualizada para guardar harmonia com a CF/88, uma vez que os conceitos que levavam em consideração apenas o sofrimento e a dor suportada pela vítima não guardam sintonia fina com o texto atual da Lei Maior. Portanto, para aquele doutrinador o dano moral caracteriza-se por toda e qualquer violação à dignidade da pessoa humana, cuja proteção recebe o máximo valor do texto constitucional atual.

Além das dores do espírito (vexame, sofrimento, humilhação e outras) surge uma nova categoria de direitos, denominados de direitos da personalidade: direito à (i) intimidade; (ii) imagem; (iii) bom nome; (iv) privacidade; (v) integridade da esfera íntima. São esses os direitos que o indivíduo tem de guardar para si, uma variadíssima quantidade de circunstâncias de sua vida privada e que a ninguém é dado o direito de emitir juízo de valor sobre tais aspectos. É bem verdade que não se trata de qualquer agressão à dignidade, mas daquela que resvala à normalidade do cotidiano da vida moderna (CAVALIERI FILHO, 2004, p. 99).

A jurisprudência brasileira, conforme pesquisa acerca do mito de uma provável existência de uma "indústria de indenizações" demonstrou ser uma inverdade, ao tempo que ficou constatado que os valores referentes a danos morais, em mais de dois terços dos casos analisados, situam-se em patamares inferiores a vinte e cinco mil reais (MENEGUIN \& BURGARIN, 2012, p. 197). 


\section{O Dano Moral e as Compensações/Indenizações no Âmbito do STJ}

No âmbito dos Tribunais Superiores, em especial, quando se tem decidido no Superior Tribunal de Justiça - STJ, basicamente duas espécies de questões chegam a esse tribunal: (i) em sede de Recurso Especial, propriamente dito, a tentativa de uma das partes em alterar o quantum indenizatório e; (ii) em sede de Embargos de Divergência, onde se alega distorções nas decisões entre Turmas ou entre estas e a Corte Especial, também retratando que em situações fáticas idênticas atribuiu-se valores desproporcionais, em relação ao dano moral.

Quanto ao primeiro caso, admite a jurisprudência do STJ, excepcionalmente, em recurso especial, reexaminar o valor fixado a título de indenização por danos morais, quando ínfimo ou exagerado. Hipótese, contudo, em que o valor foi estabelecido na instância ordinária, atendendo às circunstâncias de fato da causa, de forma condizente com os princípios da proporcionalidade e razoabilidade, conforme julgado adiante transcrito:

AgRg no REsp 1471146/AM AGRAVO REGIMENTAL NO RECURSO ESPECIAL 2014/0185082-3 - Relator Ministro Moura Ribeiro - Terceira Turma - Julgamento: 16.09.2014

AGRAVO REGIMENTAL NO RECURSO ESPECIAL. COBRANÇA INDEVIDA. DANOS MORAIS. EMBARGOS DE DECLARAÇÃO. OMISSÃO, CONTRADIÇÃO OU OBSCURIDADE. NÃO OCORRÊNCIA. NÃO INDICAÇÃO. SÚMULA 284/STF. PREQUESTIONAMENTO. AUSÊNCIA. SÚMULA 211/STJ. REEXAME DE FATOS E PROVAS. INADMISSIBILIDADE. ALTERAÇÃO DO VALOR FIXADO. IMPOSSIBILIDADE. DISSÍDIO JURISPRUDENCIAL. COTEJO ANALÍTICO E SIMILITUDE FÁTICA. AUSÊNCIA. MANUTENÇÃO INTEGRAL DA DECISÃO AGRAVADA.

1. [...]

$[\ldots]$

4. O reexame de fatos e provas em recurso especial é inadmissível.

5. A alteração do valor fixado a título de compensação por danos morais somente é possível, em recurso especial, nas hipóteses em que a quantia estipulada pelo Tribunal de origem revela-se irrisória ou exagerada.

6. O dissídio jurisprudencial deve ser comprovado mediante o cotejo analítico entre acórdãos que versem sobre situações fáticas idênticas.

7. Não tendo o recurso trazido argumentos capazes de ensejar alteração no julgamento, a decisão merece ser mantida pelos seus próprios fundamentos.

8. Agravo regimental não provido.

Quanto ao segundo caso, o STJ editou a Súmula 420 com seguinte teor: "Incabível, em Embargos de Divergência, discutir o valor de indenização por danos morais.” Portanto, 
conforme julgado que se transcreve adiante, fica bem claro o posicionamento daquela Corte nesse sentido:

AgRg nos EMBARGOS DE DIVERGÊNCIA EM RESP N $N^{\circ} 970.260$ - SP (2007/0250979-7)- Relator: Ministro Ari Pargendler. Julgamento: 12.03.2008.

EMENTA: PROCESSO CIVIL. EMBARGOS DE DIVERGÊNCIA. Os embargos de divergência não servem para a releitura do processo, só se prestando para uniformizar a jurisprudência do Tribunal. A indenização por danos morais deve ser aferida caso a caso, levando-se em consideração as peculiaridades da situação concreta. Agravo regimental não provido.

Não se pode deixar de mencionar outra questão de fundo relevante e que recorrentemente é levada à apreciação do STJ, que é o início do lapso temporal que incide a atualização monetária nas questões de condenação em dano moral. Em casos dessa natureza o STJ tem decido que a atualização monetária faz-se somente a partir decisão de primeiro grau, ocasião em que o juiz sopesou, o quantum de reparação/compensação devida à época em que a decisão que o fixou foi prolatada e não quando da ocorrência do dano ou do momento da citação. Eis adiante um julgado nesse sentido.

AgRg no REsp n.835.60/RS, relator Ministro Aldir Passarinho Júnior, DJ de26.207.

CIVL EPROCESUAL. AÇÃO DE INDENIZAÇÃO. INSCRIÇÃO DO NOME DO DEVDOR EM CADASTRO DE INADIMPLENTES. DANO INDENIZÁVEL. VALOR MÓDICO, CONSIDERANDO A INADIMPLÊNCIA ANTERIOR EO APONTAMENTO POR OUTROS CREDORES. COREÇÃO MONETÁRIA. JUROS MORATÓRIOS.

I. A indevida inscrição em cadastro de inadimplentes gera direito à indenização por dano moral, independentemente da prova objetiva do abalo à honra e à reputação sofrida pelo autor, que se permite, na hipótese, presumir, gerando direto a ressarcimento que deve, de outro lado, ser fixado sem excesso, evitando-se enriquecimento sem causa da parte atingida pelo ato ilícito, que foi observado no caso dos autos, com afixação em valor que considera existência de dívida impaga e cadastramentos promovidos por outros credores.

II. Fixado a reparação em valor determinado na decisão recorrida, correção monetária flui a partir daquela data, vedado seu cômputo retroativo.

III. Os juros de mora têm início a partir do evento danoso, nas indenizações por ato ilícito, ao teor da Súmula n.54 do STJ.

IV. Agravo parcialmente provido

\section{Análise Econômica do Direito como Meio de Efetividade da Reparação do Dano Moral}

O Estado brasileiro perdeu uma grande oportunidade ao não discutir o veto presidencial a alguns dispositivos do CDC, quando de sua promulgação, no que se refere à utilização do que seria, talvez, o primeiro pilar de responsabilidade civil, baseada numa análise 
econômica do direito. Os dispositivos vetados ${ }^{4}$ impunham uma multa civil que corresponderia a uma sanção inibitória pelas violações mais graves cometidas pelos fornecedores. O grande argumento utilizado para a redução do quantum estipulado nas indenizações é o enriquecimento sem causa, previsto no CCB/2002, em seus artigos 884/886. Por isso, os grandes conglomerados ou grupos empresariais continuam suas práticas abusivas e enganosas em detrimento do consumidor, uma vez que os tribunais estão impedidos de estipularem indenizações que possam impor freios inibitórios a tais fornecedores.

A análise econômica do direito, ainda que sob roupagem menos técnica, remonta ao século XVIII, com destaque para Adam Smith, em Lectures on Jurisprudence como em The Wealth of Nations (COOTER \& ULEN, 2010, p. 17). Entretanto, foi somente na segunda metade do século XX, que se iniciaram estudos integrativos no âmbito do direito-economia, cujos trabalhos pioneiros são de Ronald Coase e Gary Becker (Universidade de Chicago), Guido Calabresi (Universidade de Yale), dentre outros tão importantes.

Inicialmente é importante a desmistificação do fenômeno da análise econômica do direito. Não é, em absoluto, a matematização do direito, como alguns querem antever. Não se trata da priorização da maximização das riquezas simplesmente. Para RIBEIRO \& GICO JÚNIOR (2013, p. 19), a análise econômica do direito não é um fim em si mesma, mas trata-se da:

[...] aplicação do instrumental analítico e empírico da economia, em especial da microeconomia e da economia do bem-estar social, para se tentar compreender, explicar e prever as implicações fáticas do ordenamento jurídico, bem como da lógica (racionalidade) do próprio ordenamento jurídico. [...], a AED é a utilização da abordagem econômica para tentar compreender o direito no mundo e o mundo no direito.

\footnotetext{
${ }^{4} \underline{\text { Arts. 16}}, \underline{45}$ e $\$ 3^{\circ}$ do art. 52- "Art. 16 - Se comprovada a alta periculosidade do produto ou do serviço que provocou o dano, ou grave imprudência, negligência ou imperícia do fornecedor, será devida multa civil de até um milhão de vezes o Bônus do Tesouro Nacional - BTN, ou índice equivalente que venha substituí-Io, na ação proposta por qualquer dos legitimados à defesa do consumidor em juízo, a critério do juíz, de acordo com a gravidade e proporção do dano, bem como a situação econômica do responsável." - "Art. 45 - As infrações ao disposto neste Capítulo, além de perdas e danos, indenização por danos morais, perda dos juros e outras sanções cabíveis, ficam sujeitas à multa de natureza civil, proporcional à gravidade da infração e à condição econômica do infrator, cominada pelo juiz na ação proposta por qualquer dos legitimados à defesa do consumidor em juízo."Art. 52 - ........." $\$ 3^{\circ}$ - O fornecedor ficará sujeito a multa civil e perda dos juros, além de outras sanções cabíveis, se descumprir o disposto neste artigo." Razões dos vetos: "O art. 12 e outras normas já dispõem de modo cabal sobre a reparação do dano sofrido pelo consumidor. Os dispositivos ora vetados criam a figura da "multa civil", sempre de valor expressivo, sem que sejam definidas a sua destinação e finalidade.”
} 
O que na realidade os adeptos da escola da economia do direito têm tentado é criar um sistema de "paridade de armas", pois nas relações de consumo, o fornecedor analisa meticulosamente, quais os custos que poderão ser dispendidos na precaução a fim de se evitar um eventual produto ou serviço defeituoso, de tal sorte, que gere o máximo de lucratividade em seus negócios. Ou seja, o fornecedor trabalha diuturnamente com os conceitos da relação custo/benefício, que gere uma maximização dos seus lucros.

Possivelmente, nenhuma outra área do direito seja mais apropriada que as relações de consumo para o emprego da análise econômica do direito como princípio metodológico e pragmático na solução das lides, não simplesmente com o intuito da correta aplicação do direito, mas muito mais, com uma maximização do bem-estar para as partes e para o próprio ordenamento jurídico, no sentido de justiça distributiva.

No direito positivado, apenas o Código Penal traz expressamente a finalidade da sanção a ser imputada ao agente causador de um delito. E fá-lo, especialmente na parte final do caput do artigo 59: “[...] estabelecerá, conforme seja necessário e suficiente para reprovação e prevenção do crime: [...].”

É bem verdade que o sistema penal por sua própria natureza é tarifário. O legislador ao estabelecer o intervalo de 6 (seis) a 20 (vinte) anos de reclusão para o crime de homicídio simples, deixou muitíssimo claro que o juiz ao estabelecer a sanção não poderá desviar-se desse intervalo.

No âmbito do direito civil, especialmente nos danos de natureza patrimonial, o CCB/2002, estabeleceu em seu artigo 944, que "a indenização mede-se pela extensão do dano". Essa indenização, porém, é de natureza ressarcitória, pois que não se aplica ao dano moral que não é indene. Ao dano moral, aplica-se a compensação pecuniária, considerando que a dor ou o sofrimento são imensuráveis economicamente. Entretanto, a todas as formas de sanções não se pode perder de vista, sua finalidade: “o necessário e suficiente para reprovação e prevenção”.

Assim, tem-se que em termos de responsabilidade civil, especialmente, nos danos morais, deverá se levar em conta, uma sanção tal, capaz de produzir um desestímulo ao fornecedor, de sorte que sua equação econômica (custo/benefício) seja deficitária a ponto de 
que o custo com a precaução a impedir a remessa de um produto defeituoso ou viciado não possa maximizar seus lucros.

Essa polêmica teria sido amenizada caso o Projeto de Lei 6.960/2002, de autoria do ex-deputado Ricardo Fiúza, falecido em 2005, tivesse sido aprovado, que dentre outras modificações propostas, acrescentava ao CCB/2002, em seu artigo 944, um segundo parágrafo com o seguinte texto: "A reparação do dano moral deve constituir-se em compensação ao lesado e adequado desestímulo ao lesante". Entretanto, tal projeto foi arquivado em 14.03.2008, por inconclusão de tramitação naquela legislatura. Outro projeto $(3.880 / 2012)^{5}$, de autoria do Deputado Domingos Neto, tramita com a mesma finalidade, embora com texto distinto, daquele previsto no PL 6.960/2002.

A análise econômica do direito é o instrumento necessário e indispensável para traçar os parâmetros mais próximos ao atingimento da função punitiva e pedagógica da indenização, carregando o máximo de eficiência para a concretização da maximização do bem-estar social.

Segundo Posner (2007, p. 474) todo indivíduo, exceto aqueles que não dispõem de algum entendimento da vida (nesse grupo estão os perturbados mentais e as crianças nos primeiros anos de vida) são maximizadores racionais de suas respectivas satisfações. Assim, entre as mais diversas formas e maneiras que se apresenta à vida, o indivíduo faz uma eleição daquela que maior satisfação lhe traz. Isso ocorre, recorrentemente, o dia todo com todas as pessoas, de regra. E assim, conclui o autor que "a análise econômica do direito entende que a conduta legal ou ilegal de um indivíduo é decidida a partir de seus interesses e dos incentivos que encontra para efetuá-la ou não”.

Para Cooter \& Ulen (2010, p. 332), “o modelo econômico do direito de responsabilidade civil baseia-se nos mais simples elementos: no custo do dano e no custo de se evitar o dano". Em nosso atual sistema jurídico, notadamente, no concernente à responsabilidade civil em decorrência de danos morais, nota-se claramente, que o fornecedor tem feito sistematicamente seus cálculos, fazendo opção entre os custos que gastaria com a precaução e aqueles decorrentes de prováveis indenizações. Chega-se à conclusão que o risco

\footnotetext{
5 Art. 944. A indenização mede-se pela extensão do dano em todos os seus aspectos, seja ele moral, material, estético ou social.

Parágrafo único. Se houver excessiva desproporção entre a gravidade da culpa e o dano, poderá o juiz reduzir, eqüitativamente, a indenização ou aumentá-la com o intuito de atingir a função punitiva e pedagógica da indenização.
} 
probabilístico de ter que arcar com indenizações que superem os custos com a precaução é ínfimo, notadamente em decorrência das baixas indenizações decididas pelos tribunais brasileiros.

\section{Conclusões}

A responsabilidade civil é tema de importância singular no cotidiano da sociedade moderna. O complexo das relações que interagem entre os indivíduos, empresas e governos, sejam de natureza econômica ou social são infinitamente maiores que há pouco mais de duas décadas. Tendo ganhado dimensão global a partir da mundialização dos negócios e do comércio com o advento da rede mundial de computadores - a internet.

Sendo o homem um ser eminentemente gregário, dessas intensas relações, há imaginarse constantes conflitos, decorrentes dos mais variados graus de motivos (egoísmo, ganância, ausência de boa-fé, desonestidade, inveja e outros mais). Com isso, o Estado, detentor do monopólio da violência, tem a atribuição de resolver tais conflitos. E um desses mecanismos de solução é a responsabilização daqueles que eventualmente tenham causado prejuízos a outrem.

Verificou-se também, pelo estudo levantado que os atuais métodos e soluções apresentados pela legislação vigente e endossados pelos tribunais têm sido insuficientes para desestimular a repetição dos ilícitos causados pelas lesões que levam ao consumidor a suportar prejuízos, cujas decisões não compensam a dor e o sofrimento do lesado.

E principalmente em decorrência desse fato, pode se concluir com razoável margem de certeza, a necessidade da utilização de outros instrumentos capazes de refrear os comportamentos ilícitos dos fornecedores de bens e serviços com o objetivo de trazer uma paz social eficiente e eficaz.

É fato, porém, que a análise econômica do direito não é uma unanimidade nacional. Críticos apaixonados debatem a intromissão de outra ciência na seara jurídica e por isso tentam desconstruir suas bases de sustentação. Também é fato que os modos atuais de solução de conflitos não têm sido suficientes para reduzir as recorrentes violações aos direitos dos consumidores. E não só por isso, mas também em decorrência desse fenômeno urge que colha auxílio em outros ramos do conhecimento como auxílio instrumental ao atingimento dos seus fins: o bem comum e justiça. 


\section{Referências}

ALVIM, Eduardo Arruda. Responsabilidade Civil pelo fato do produto no CDC. In: Revista de Direito do Consumidor. São Paulo: RT, n. 15, p. 15-130, jul./set., 1995.

ARROW, Kenneth J. A difficulty in the concept of social welfare. The journal of political economy, v. 58, n. 4, Aug., 1950, p. 328-346.

BLAUG, Mark. The methodology of economics - or how economists explain. 2. ed. Cambridge Surveys of Economic Literature. Cambridge: Cambridge University, 1992, pp. 350

BRASIL. Superior Tribunal de Justiça. Agravo Regimental no REsp 1471146/AM, da Terceira Turma do Superior Tribunal de Justiça, Brasília, DF, 16 de setembro de 2014. Disponível em: <http://www.stj.jus.br>. Acesso em: 20 set. 2014.

BRASIL. Superior Tribunal de Justiça. Agravo Regimental em Embargos de Divergência no REsp 1471146/AM, da Segunda Seção do Superior Tribunal de Justiça, Brasília, DF, 12 de março de 2008. Disponível em: <http://www.stj.jus.br>. Acesso em: 20 set. 2014.

BITTAR, Carlos Alberto. Reparação civil por danos morais. 2. ed. São Paulo: RT, 1994.

CAHALI, Yussef Said. Dano moral. 2. ed. São Paulo: Revista dos Tribunais, 1999.

CAVALIERI FILHO, Sérgio. Programa de responsabilidade civil. 5. ed. São Paulo: Malheiros Editores, 2004.

COOTER, Robert; ULEN, Thomas. Direito \& economia. 5. ed. Porto Alegre: Bookman, 2010.

FRANÇA, Rubens Limingi. Manual de direito civil. 3. ed. São Paulo: Editora Revista dos Tribunais, 1975, v. 1.

GARCIA, Leonardo de Medeiros. Direito do consumidor: código de defesa do consumidor. 2. ed. Niteroi, RJ: Impetus, 2006.

GONÇALVES, Carlos Roberto. Responsabilidade civil. 11. ed. São Paulo: Saraiva, 2009.

GRINOVER, Ada Pellegrini [et al.]. Código brasileiro de defesa do consumidor: comentado pelos autores do anteprojeto. 5. ed. Rio de Janeiro: Forense, 1997.

MENEGUIN, Fernando B.; BURGARIN, Maurício. Um modelo econômico para a responsabilidade civil na defesa do consumidor. Brasília: EALR, v. 3, n. 2, p. 189-205, JulDez, 2012.

NERY JÚNIOR, Nelson. Os princípios gerais do código brasileiro de defesa do consumidor. RDC. São Paulo: RT, vol. 3, 1992.

PEREIRA, Caio Mário da Silva. Responsabilidade civil. 9. ed. Rio de Janeiro: Forense, 1998.

POSNER, Richard A. Problemas de filosofia do direito. São Paulo: Martins Fontes, 2007.

Revista de Direito, Glob. R Res nas Rel de Cons | e-ISSN: 2526-0030 | Brasília | v. 2 | n. 1| p. 57-72 |Jan/Jun. 2016. 
RIBEIRO, Ferreira Gustavo; GICO JÚNIOR, Ivo T. O jurista que calculava. Curitiba: CRV, 2013.

RIBEIRO, Márcia Carla Pereira; GALESKI, Irineu Júnior. Teoria Geral dos Contratos. Contratos empresariais e análise econômica. Ed. Elsevier. 2009, p. 89.

STOCO, Rui. Tratado de responsabilidade civil. 6. ed. rev.. atual. e ampl. São Paulo: RT, 2004.

TEPEDINO, Gustavo; BARBOZA, Heloisa Helena; MORAES, Maria Celina Bodin de. Código civil interpretado conforme a constituição da república. Vol. II. Rio de Janeiro: Renovar, 2006.

THEODORO JÚNIOR, Humberto. Direitos do consumidor: a busca de um ponto de equilíbrio entre as garantias do código de defesa do consumidor e os princípios gerais do direito civil e do direito processual civil. 5. ed. Rio de Janeiro: Forense, 2008. 